\title{
The Gender Dimensions of Poverty and Climate Change Adaptation
}

\author{
Justina Demetriades and Emily Esplen*
}

\begin{abstract}
1 Introduction
It is generally recognised that it is those who are already poor and marginalised who experience the impacts of climate change most acutely (see Tanner and Mitchell this IDS Bulletin, 'Entrenchment or Enhancement'; GTZ in Lambrou and Piana 2006), and are in the greatest need of adaptation strategies in the face of shifts in weather patterns and resulting environmental phenomena. At the same time, it is the poor and marginalised who have the least capacity or opportunity to prepare for the impacts of a changing climate or to participate in national and international negotiations on tackling climate change issues.
\end{abstract}

As is frequently argued in gender analyses of climate variability and change, women and girls make up a disproportionate number of the 'poor or marginalised' (see, e.g. Mitchell et al. 2007). This is due to multiple poverty-inducing/exacerbating disadvantages caused by pervasive gender inequalities. Such inequalities can give rise to higher rates of poverty among women relative to men, and a more severe experience of poverty by women than men - for female household heads, and also among women and girls living within male-headed households considered to be non-poor due to unequal intra-household distribution of power and resources, such as food and property (Kabeer 2008; Chant 2007). Where women and girls have fewer capabilities and resources than men, this undermines their capacity to adapt to existing and predicted impacts of climate change, or to contribute important knowledge and insights to adaptation and mitigation decision-making processes.

Drawing on available literature on gender and climate change, this article seeks to unpack in concrete ways the interlinkages between gender inequalities, poverty and the differential capacity of women and men to adapt to or mitigate the very real challenges posed by climate change. While there is little existing research considering the linkages between climate change, poverty and gender explicitly, there is a wealth of literature relating to gender and agriculture, land, water management, forestry, migration and livelihoods. Moreover, gender analyses have for decades been surfacing the social, economic and political inequalities that both comprise and contribute to the multiple dimensions of poverty and constrain development processes and outcomes. As pro-poor adaptation fast becomes a priority, those researching and working on climate change adaptation can draw from these existing analyses to help ensure that climate change processes and outcomes are equitable, efficient and effective. At the same time, the growing awareness of the need to ensure that climate change adaptation and mitigation processes are inclusive of poor and marginalised people's needs provides an opportunity for gender advocates to insist that the priorities of poor women and men are heard and taken seriously.

\section{Problems with the existing analysis}

While there is much that can be learnt from the existing body of work on gender and the environment, there are also weaknesses - most notably the heavy reliance on generalisations which cannot hold true for all people in all places. The tendency has been to conceptualise women everywhere as a homogenous, subjugated group 'the poorest of the poor'. Such representations are problematic on multiple accounts, particularly in their failure to account for the complex interactions between gender and other forms of disadvantage based on class, age, 'race'/ethnicity and sexuality. Intersecting inequalities produce differing experiences of power and powerlessness between 
and among diverse groups of women and men, which in turn enable or deny them certain choices for example determining whether migration in the face of environmental degradation is a viable option (for the elderly or very young, those with limited resources, or those facing cultural or religious restrictions on their mobility it may not be). Further, it is commonly recognised that the type and severity of climate change impacts are contextually variable. Thus women in rural Bangladesh may face a different set of challenges and articulate different priorities to women in other regions - or indeed to women living in urban Bangladesh. As such, premising advocacy messages on sweeping generalisations neither makes a concrete case for the need for gender mainstreaming in climate change processes, nor does it help to identify practical steps to reduce gendered vulnerability and build adaptive capacity at household and community levels.

Intersecting inequalities also mean that while men in most societies enjoy the benefits of male privilege, they may share with the women in their lives similar experiences of indignity and subordination as a result of discrimination or social and economic oppression (Esplen and Greig 2008). Experiences of powerlessness can leave men and boys, like women and girls, vulnerable to climate change, albeit often in different ways. Despite this, there is a dearth of research exploring the ways in which notions of masculinity shape men's gendered risks, capabilities and priorities in the face of environmental change. The default response has been to talk about women and their vulnerabilities - not surprising given the entrenched structural disadvantages faced by women in many societies. Yet, the inadequacies of focusing on women in isolation have long been recognised in gender and development circles: women live in communities, they live in families, they live with men. Abstracting women from their social realities eclipses the relational nature of gendered power and the interdependency of women and men, and paints a distorted picture of women's vulnerabilities, choices and possibilities (Esplen with Brody 2007: 2). So rather than discounting men in gender analyses of climate change as if they are somehow nongendered, we need to find spaces within gender and climate change frameworks to acknowledge and communicate men's vulnerabilities where they do exist, and to recognise the positive contributions that men can and are making to gender equality and sustainable environment goals.
While this article does not claim to 'fill' these gaps, it does make an urgent call for more context-specific research drawing on local realities and coping strategies, and argues for a move away from a narrow preoccupation with women alone towards a more complex understanding of the relational nature of gendered power. It is precisely this kind of contextualised research that is needed if we are to move away from generalised statements and slogans, towards more nuanced and concrete understandings of how gender-related constraints play out in particular contexts of environmental stress - to better inform policy and practice.

\section{The gender-poverty-climate change nexus}

Taking a multidimensional approach to poverty, which goes beyond conceptualising poverty only in terms of monetary income, Robert Chambers' Web of Poverty's Disadvantages (2005: 46) outlines multiple dimensions of poverty, including poverty of time, lack of political clout, insecurities, physical illbeing, material poverties, ascribed and legal inferiority, and social relations. Each dimension intersects with gender and other forms of inequality (class, age, 'race'/ethnicity and sexuality), with implications for women's and men's vulnerability to - and capacity to adapt to - climate change. At the same time, climate change can exacerbate existing inequalities between and among women and men and intensify gendered experiences of poverty. This section presents some of the connections between poverty, gender inequality, and vulnerability/resilience to environmental stress and shocks.

\subsection{Physical and mental health}

The likely health consequences of climate change include higher rates of malnutrition due to food shortages, increases in heat-related mortality and morbidity, higher levels of waterborne diseases, and increases in respiratory disease where air pollution worsens (Confalonieri et al. 2007). Gender discrimination in the allocation of household resources, including those relating to nutrition and medicines, may put girls at greater risk than boys. In many societies, women and girls also face social and material barriers to accessing healthcare services due to limited economic assets with which to pay for healthcare, as well as cultural and/or religious restrictions on their mobility, which may inhibit them from travelling to clinics without permission from and accompaniment by a male family member. 
Elderly women are likely to be particularly vulnerable to climate-related health impacts such as heat stress and malnutrition, and may lack access to and knowledge of how to use public, community and private sector services, including health services. Elderly women are more vulnerable to economic and social deprivation than elderly men due to the cumulative effect of relatively poor access to employment and education over their life cycle. As such, they may not be able to afford to pay even nominal amounts for clinic visits and drugs. Programmes are therefore needed to improve access to health services, particularly for the elderly, including introducing cash transfers, free health checks and mobile health units.

It is not only women who are affected, however. Research from many parts of the world has shown that men and boys also face social barriers to using health services - notably the fear of being seen as weak or needing support (Esplen 2006). A decline in food security and livelihood opportunities can also cause considerable stress for men and boys given the social expectation that they will provide economically for the household, leading to mental ill health in some cases. It has been recognised that men and boys are less likely to seek help for stress and mental health issues than women and girls (Masika 2002), meaning that preparation for, and responses to, climate change need to be sensitive to gender differentials in healthcare (including mental) -seeking behaviour.

\subsection{Ascribed and legal inferiority}

For households dependent on agriculture, land is the most important productive asset (World Bank 2007). Yet statutory and/or customary laws restrict women's land rights in many parts of the world, which in turn can make it difficult for women farmers to access credit. Research suggests that women receive less than 10 per cent of the credit granted to small farmers in Africa (Sexton et al. 2004 cited in Randriamaro 2006), without which they cannot buy the crucial inputs needed to adapt to environmental stress, such as new varieties of plant types and animal breeds intended for higher drought or heat tolerance, and new agricultural technologies (APF and NEPAD 2007). These obstacles are further exacerbated by gender biases in institutions which often reproduce assumptions that men are the farmers (Gurung et al. 2006). The result is that agricultural extension services and technologies are rarely available to women farmers (Lambrou and
Piana 2006). Without access to land, credit and agricultural technologies, women farmers face major constraints in their capacity to diversify into alternative livelihoods.

This can be particularly problematic for single parent households headed by women who cannot rely on male household members to purchase crucial inputs. Moreover, numbers of female-headed households often increase when livelihoods are in jeopardy and men out-migrate for work, resulting in women becoming de facto heads of households and taking on men's farming roles in addition to their existing agricultural and domestic responsibilities (Laudazi 2003). It may be difficult for a household that is treated as female-headed in a husband's absence to retain control over land and other productive assets because of restrictions on women's property and land rights. This heightens women's vulnerability at exactly the point at which their responsibilities increase.

Despite these obstacles, recent evidence demonstrates that women who are already experiencing the effects of weather-related hazards - such as erratic monsoon patterns, flooding, and extended periods of drought - are developing effective coping strategies, which include adapting their farming practices (see Mitchell et al. 2007). More research is needed into the adaptation strategies of women and men at household and community levels in the face of existing climate change impacts on agricultural productivity and food security, including how these are manifested in different contexts: What aspects of women's and men's agricultural knowledge have been overlooked and could contribute to effective adaptation? What are women and men already doing and what do they identify as their needs and priorities? Future adaptation and/or agriculture policies should explicitly draw on these insights and seek to better support these existing localised strategies.

\subsection{Discrimination in the labour market}

Women's unequal access to economic resources such as land and property is exacerbated by widespread labour market discrimination. Although female labour force participation is increasing in almost every region of the world' (Kabeer 2007, 2008; Pearson 2007), women continue to be restricted to mostly lowstatus and poorly paid jobs, and they dominate in the informal employment sector, ${ }^{2}$ which is often worst hit 
by climate change-related disasters and other shocks (Araujo et al. 2007). When coupled with the interrupted nature of women's work due to childcare and other domestic responsibilities, women's capacity to accumulate savings is limited - reducing their means for coping with insecurity. $A$ trend of rising male unemployment or underemployment in many countries (see, e.g. Silberschmidt's 2004 account of male unemployment in East Africa) further undermines the resilience of households to adapt in the face of environmental stress and shocks.

\subsection{Poverty of time}

The time available for women and girls to take up income-generating activities is further restricted by their socially ascribed gender responsibilities to care for the sick, particularly in times of disaster and environmental stress, and to carry out domestic tasks such as collecting fuel and water (Araujo et al. 2007). In drought-prone regions affected by desertification, the time absorbed by water and fuel collection will increase as women and girls will have to travel greater distances. The heavy rainfalls and more frequent floods projected to result from climate change in many areas will also increase women's workloads, as more time will be taken up cleaning and maintaining houses after flooding. This limits the time available for income generation with huge financial implications for household viability, especially for female-headed households which lack the contribution of an adult male earner. Care obligations may also constrain opportunities to contribute to community-level decision-making processes on climate change or disaster risk reduction. This results in women's specific needs and priorities being overlooked, undermining the effectiveness of responses by failing to incorporate all relevant knowledge. Programmes to offset the demands of care work on women and girls are therefore critical. Considerable knowledge already exists regarding appropriate support and interventions to alleviate women's care burden in contexts of high HIV and AIDS prevalence (see, e.g. Esplen 2008; VSO 2006). These insights should be drawn upon to inform climate change policy and programming.

\subsection{Lack of political clout}

In the context of climate change, women and girls have remained conspicuously absent from decisionmaking processes at all levels. For example, at the 2007 Thirteenth Session of the Conference of the
Parties (COP-13) in Bali, women comprised only 28 per cent of delegation parties and 12 per cent of heads of delegations (Ulrike Röhr, personal communication 2008). There are also numerous examples of cases where women have not been consulted in the design and planning of community level water or agricultural initiatives because this would require them stepping outside their traditional, non-public roles into public and technical arenas for which they are seen as 'unqualified' and 'unsuited' (Fisher 2006). Lack of opportunity to feed knowledge into community or national-level adaptation and mitigation strategies could in fact jeopardise larger processes of reducing climate change and its impacts and undermine the effectiveness of projects at the local level. In the Kilombero district of Tanzania, for example, after a well built by a non-governmental organisation (NGO) dried up shortly after it was created, it was revealed that the location of the well had been decided by an all-male local committee. When development workers talked to the local women, they discovered that it is often the women's task to dig for water by hand and consequently they know the places which provide the best water yields. Since the incident, women have had more involvement in decisions about the location of wells (Fisher 2006: 5-6).

Although it cannot be assumed that women will automatically know or represent poor women's concerns, achieving a gender balance in participation in climate change negotiations and representation at decision-making tables is a good starting point and is key to successful interventions (Villagrasa 2002: 41, cited in Dennison 2003; Polack, this IDS Bulletin). Promoting women's and girl's meaningful participation in decision-making also contributes to addressing gender inequalities by raising the profile and status of women and girls in the community and challenging traditional assumptions about their capabilities.

To design gender-sensitive responses to climate change, we thus need to locate and hear existing knowledge on climate change, including local practices and indigenous knowledge. Critical questions for future research include: What are the current levels of female participation in decisionmaking on climate change at local, regional, national and international levels - in terms of numbers and the quality of participation? What are the barriers to participation; or, for those present, the barriers to 
being heard and taken seriously? What can be learnt from existing literature on promoting women's and youth's participation in decision-making?

\subsection{Insecurities - climate change-related conflict} It is well recognised that climate change will - and is already - resulting in a growing scarcity of natural resources such as water and arable land, in some parts of the world. With heightened competition over diminishing and unequally distributed resources, conflict over resources is set to increase (Hemmati 2005; Reuveny 2007; Röhr 2008). Although there is currently little research explicitly linking climate change with both conflict and gender, there is a considerable body of existing work on gender and conflict which points to the different roles women and men play in conflicts and to the differential impacts of conflict on men and women. In Darfur, sexual violence against women and girls (and less documented, against boys and men)-occurring in villages, in and around refugee and internally displaced persons (IDP) camps, and outside camps at times when scarce fuel and water is being collected - provides a stark example of one of the likely gendered effects of increased climate changerelated conflicts.

It is critical that we draw insights and lessons from the existing literature to strengthen responses to climate change-related conflict. One innovative area of existing work is around engendering conflict early warning systems. The United Nations Development Fund for Women (UNIFEM) has developed a set of gender-sensitive early warning indicators which include increased gender-based violence, increased unemployment among male youths, reduced trust between ethnic groups, and a reduction in women's involvement over land disputes (Moser 2007). Many of these indicators reflect the projected effects of climate change on communities - particularly around depleting resources.

Research is further needed to establish how best to respond to violent conflict over natural resources in a gender-sensitive way, taking into account the needs of women and girls, boys and men. Finally, it is essential that research is undertaken into the impacts of natural resource depletion on intra-household conflict. This is in order to establish policies and practices which lessen the likelihood of arguments over scarce natural resources which may result in gender-based violence.
3.7 Insecurities - climate change-related disasters Gender inequality is also a major factor contributing to vulnerability in disaster situations, such as Hurricanes Mitch and Katrina and flooding in South and East Asia, that are being increasingly linked to climate change. According to a recent report, women and children are 14 times more likely to die than men during disasters (Araujo et al. 2007). Women and girls' particular vulnerability is due to differences in socialisation where girls are not equipped with the same skills as their brothers, such as swimming and tree climbing. For example, it has been well documented that women in Bangladesh did not leave their houses during floods due to cultural constraints on female mobility, and that those who did were unable to swim (Röhr 2006).

Research shows that gender inequalities can also be exacerbated in the aftermath of disasters. For example, there is evidence that women and girls are more likely to become victims of domestic and sexual violence after a disaster, particularly when families have been displaced and are living in overcrowded emergency or transitional housing where they lack privacy. Adolescent girls report especially high levels of sexual harassment and abuse in the aftermath of disasters and complain of the lack of privacy they encounter in emergency shelters (Bartlett 2008). The increase in violence is often partly attributed to stress caused by men's loss of control in the period following a disaster, compounded by longer-term unemployment or threatened livelihoods.

Helpful responses, especially for older girls and women, may involve working with girls on ways to protect them from these potential abuses. This could involve lighting the way to the toilets, or finding people who are willing to monitor the route or accompany children, adolescent girls and women. It can also mean finding ways to ensure their privacy while they are bathing or dressing (Bartlett 2008).

\section{Key conclusions and recommendations for future research}

Despite these obstacles, recent evidence demonstrates that women and men who are already experiencing the effects of weather-related hazards - such as erratic monsoon patterns, flooding and extended periods of drought - are developing effective coping strategies, which include adapting their farming practices. This emerged clearly in a recent participatory research project by ActionAid 
and IDS with women in rural communities in the Ganga river basin in Bangladesh, India and Nepal (Mitchell et al. 2007). The women who took part in the research described various adaptation strategies to secure their livelihoods in the face of changes in the frequency, intensity and duration of floods, such as changing cultivation to flood- and droughtresistant crops, to crops that can be harvested before the flood season, or to varieties of rice that will grow high enough to remain above the water when the floods come. As one woman explained:

As we never know when the rain will come, we had to change. I started to change the way I prepare the seedbed so that we don't lose all our crops. I am also using different crops depending on the situation. (Mitchell et al. 2007: 6)

The women were also clear about what they need in order to adapt better to the floods: crop diversification and agricultural practices, but also skills and knowledge training to learn about flood and drought-resistant crops and the proper use of manure, pesticides and irrigation. Clearly, these women have a great deal of knowledge and experience of coping with the particular impacts of climate change in a specific context, and understand their needs and the types of interventions required for ensuring more sustainable agricultural processes in the face of these changes (Mitchell et al. 2007). This reaffirms the point made repeatedly in the

\section{Notes}

* This article draws heavily on Brody, Demetriades and Esplen (2008).

1 The exceptions are the transitional economies in Eastern Europe and Central/Western Asia where there have been reversals, and the Middle East literature on gender and the environment that women and men have distinct and valuable knowledge about how to adapt to the adverse impacts of environmental degradation (Laudazi 2003; Gurung et al. 2006; WEDO 2003).

It is critical that this kind of context-specific knowledge and experience be captured through further participatory research into women's and men's existing coping strategies and adaptation priorities, especially within sub-Saharan Africa where to our knowledge there has been no documented research that has specifically set out to ask women and men what they want. Participatory research into the specific challenges and strategies adopted by women and men in urban contexts should also be a priority.

Further concerted efforts are needed to link research findings to policy and implementation so that they do not simply evaporate. This is critical and requires investment in building the capacity of women and men to have the skills and confidence to engage with climate change debates at the local, national, regional and international levels, for example through supporting grassroots awareness raising, confidence-building, and advocacy and leadership training programmes. If we are to genuinely move towards more equitable, appropriate and effective climate change policies and programmes, this is perhaps the single most important step.

and North Africa where they remain low (Kabeer 2008).

2 Some 60 per cent of women in the developing world are in informal employment outside of agriculture, except in North Africa (43 per cent) (Kabeer 2008: 39) 


\section{References}

APF (Africa Partnership Forum) and the New Partnership for Africa's Development (NEPAD) Secretariat (2007) 'Gender and Economic Empowerment in Africa', 8th Meeting of the Africa Partnership Forum, Berlin, Germany, 22-23 May 2007, APF, www. africapartnershipforum.org/ dataoecd/57/53/38666728.pdf (accessed 8 July 2008)

Araujo, A. and Quesada-Aguilar, A., with Aguilar, L. and Pearl, R. (2007) Gender Equality and Adaptation, Women's Environment \& Development Organization (WEDO) and the International Union for Conservation of Nature (IUCN), USA, www.genderandenvironment.org/admin/admin biblioteca/documentos/Factsheet\%20Adaptation.pdf (accessed 8 July 2008)

Baden, S. with Milward, K. (1997) Gender Inequality and Poverty: Trends, Linkages, Analysis and Policy Implications, BRIDGE Report 30 (revised), Brighton: BRIDGE - IDS, www.bridge.ids.ac.uk/ reports/re30.pdf (accessed 8 July 2008)

Bartlett, S. (2008) Climate Change and Urban Children: Impacts and Implications for Adaptation in Low and Middle Income Countries, International Institute for Environment and Development (IIED) Human Settlements Discussion Paper - Climate Change 2, London: IIED, www.iied.org/pubs/ display.php?o=10556IIED (accessed 8 July 2008)

Brody, A.; Demetriades, J. and Esplen, E. (2008) 'Gender and Climate Change: Mapping the Linkages - A Scoping Study on Knowledge and Gaps', draft, Brighton: BRIDGE - IDS, www.bridge.ids.ac.uk/reports/Climate_Change_ DFID_draft.pdf (accessed 8 July 2008)

Chambers, R. (2005) 'Participation, Pluralism and Perceptions of Poverty', paper for the Many Dimensions of Poverty Conference, Brazil, August

Chant, S. (2007) 'Dangerous Equations? How Female-headed Households Became the Poorest of the Poor: Causes, Consequences and Cautions', in A. Cornwall, E. Harrison and A. Whitehead, Feminisms in Development: Contradictions, Contestations and Challenges, London/New York: Zed Books

Confalonieri, U.; Menne, B.; Akhtar, R.; Ebi, K.L.; Havengue, M.; Kovats, R.S.; Revich, B. and Woodward, A. (2007) 'Human Health', in M.L. Parry, O.F. Canziani, J.P. Palutikof, P.J. van der Linden and C.E. Hanson (eds) Climate Change 2007: Impacts, Adaptation and Vulnerability. Contribution of Working Group II to the Fourth
Assessment Report of the Intergovernmental Panel on Climate Change, Cambridge: Cambridge University Press: 391-431

Dennison, C. (2003), 'From Beijing to Kyoto: Gendering the International Climate Change Negotiation Process', paper presented at 53rd Pugwash Conference on Science and World Affairs - Advancing Human Security: The Role of Technology and Politics, www.pugwash.org/ reports/pac/53/dennison.htm (accessed 8 July 2008)

Esplen, E. (2008 forthcoming) 'Gender and Care Overview Report', Gender and Care Cutting Edge Pack, Brighton: BRIDGE - IDS

Esplen, E. (2006) Engaging Men in Gender Equality: Positive Strategies and Approaches - Overview and Annotated Bibliography, BRIDGE Bibliography 15, Brighton: BRIDGE - IDS, www.bridge.ids.ac.uk/ reports/BB15Masculinities. pdf (accessed 8 July 2008)

Esplen, E. with Brody, A. (2007) Putting Gender Back in the Picture: Rethinking Women's Economic Empowerment - Overview and Annotated Bibliography, BRIDGE Bibliography 19, Brighton: BRIDGE - IDS, www. bridge.ids.ac.uk/reports/ BB19_Economic_Empowerment.pdf (accessed 8 July 2008)

Esplen, E. and Greig, A. (2008) Politicising Masculinities: Beyond the Personal, Brighton: IDS, www.siyanda.org/docs/esplen_greig_masculinities.pdf (accessed 8 July 2008)

Fisher, J. (2006) For Her It's the Big Issue: Putting Women at the Centre of Water Supply, Sanitation and Hygiene, Switzerland: Water Supply and Sanitation Collaborative Council, http://wash-cc.org/pdf/ publication/FOR_HER_ITs_THE_BIG_ISSUE_ Evidence_Report-en.pdf (accessed 8 July 2008)

Gurung, J.D.; Muanundu, S.; Lubbock, A.; Hartl, M. and Firmian, I. (2006) Gender and Desertification: Expanding Roles for Women to Restore Drylands, Rome: International Fund for Agricultural Development (IFAD), www.ifad.org/pub/gender/ desert/gender_desert.pdf (accessed 8 July 2008)

Hemmati, M. (2005) Gender and Climate Change in the North: Issues, Entry Points and Strategies for the Post-2012 Process and Beyond, Berlin: Genanet/ Focal Point Gender Justice and Sustainability Kabeer, N. (2008) Mainstreaming Gender in Social Protection for the Informal Economy, New Gender Mainstreaming Series on Development Issues, London: Commonwealth Secretariat 
Kabeer, N. (2007) Marriage, Motherhood and Masculinity in the Global Economy: Reconfigurations of Personal and Economic Life, IDS Working Paper 290, Brighton: IDS

Lambrou, Y. and Piana, G. (2006) Gender: The Missing Component of the Response to Climate Change, Rome: Food and Agriculture Organization of the United Nations (FAO), www.fao.org/sd/dim_pel/ docs/pe1_051001d1_en.pdf (accessed 8 July 2008)

Laudazi, M. (2003) Gender and Sustainable Development in Drylands: An Analysis of Field Experiences, Rome: Food and Agriculture Organization (FAO), www.fao.org/docrep/005/ j0086e/j0086e00.htm (accessed 8 July 2008)

Masika, R. (2002) 'Editorial 2', in 'Gender, Development and Climate Change', Oxfam Gender and Development Journal 10.2, Oxford: Oxfam, www.oxfam.org.uk/resources/downloads/ FOG_Climate_15.pdf (accessed 8 July 2008)

Mitchell, T.; Tanner, T. and Lussier, K. (2007) 'We Know What We Need!' South Asian Women Speak Out on Climate Change Adaptation, Action Aid International and IDS, www.ids.ac.uk/UserFiles/ File/poverty_team/ActionAid_IDS_Report_We_ know_what_we_need_South_Asian_women_ speak_out_on_climate_change_adaptation.pdf (accessed 8 July 2008)

Moser, A. (2007) 'Gender and Indicators Overview Report', Gender and Indicators Cutting Edge Pack, Brighton: BRIDGE - IDS, www.bridge.ids.ac.uk/ reports_gend_CEP.html (accessed 8 July 2008)

Pearson, R. (2007) 'Re-assessing Paid Work and Women's Empowerment: Lessons from the Global Economy', in A. Cornwall, E. Harrison and A. Whitehead (eds) Feminisms in Development: Contradictions, Contestations and Challenges, London/New York: Zed Books

Randriamaro, Z. (2006) 'Gender and Trade Overview Report', Gender and Trade Cutting Edge Pack, Brighton: BRIDGE - IDS, www.bridge.ids.ac.uk/ reports/CEP-Trade-OR.pdf (accessed 8 July 2008)
Reuveny, R. (2007) 'Climate Change-induced Migration and Violent Conflict', Political Geography 26: 656-73, the Netherlands: Elsevier

Röhr, U. (2008) 'Gender Aspects of Climate Induced Conflicts', Environment and Conflict Special Edition Newsletter on 'Gender, Environment, Conflict', Germany: Adelphi Research

Röhr, U. (2006) 'Gender and Climate Change - A Forgotten Issue?', Tiempo: Climate Change Newsletter 59, University of East Anglia, International Institute for Environment and Development (IIED), Stockholm Environment Institute (SEI), www.tiempocyberclimate.org/ newswatch/comment050711.htm (accessed 8 July 2008)

Silberschmidt, M. (2004) 'Masculinities, Sexuality and Socio-economic Change in Rural and Urban East Africa', in S. Arnfred (eds), Re-thinking Sexuality in Africa, Sweden: Nordiska Afrikaininstitutet

Tanner, T.M. and Mitchell, T. (2008) Entrenchment or Enhancement: Could Climate Change Adaptation Help Reduce Chronic Poverty?, Working Paper 106, Manchester: Chronic Poverty Research Centre VSO (2006) Reducing the Burden of HIV and AIDS Care on Women and Girls, Voluntary Services Overseas (VSO) Policy Brief, London: VSO, www.vso.org.uk/Images/ RBHACWG_tcm88415.pdf (accessed 8 July 2008)

WEDO (2003) Common Ground, Women's Access to Natural Resources and the United Nations Millennium Development Goals, New York: Women's

Environment \& Development Organization, www.wedo.org/files/common_ground.pdf (accessed 8 July 2008)

World Bank (2007) Global Monitoring Report 2007 Millennium Development Goals: Confronting the Challenges of Gender Equality and Fragile States, Washington DC: World Bank 